\title{
The effect of $\mathrm{BaTiO}_{3}$ particle shape on complex permittivity of $0.98 \mathrm{MgTiO}_{3}-\mathrm{O.02}_{\mathrm{BaTiO}}$ composite powders at $\mathrm{GHz}$ frequencies
}

\author{
M. Tuhkala ${ }^{1, \text { a) }}$, M. Maček ${ }^{2}$, T. Siponkoski ${ }^{1}$, J. Juuti ${ }^{1}$, M. Teirikangas ${ }^{1}$, \\ D. Suvorov ${ }^{2}$ and H. Jantunen ${ }^{1}$ \\ ${ }^{1}$ Microelectronics and Materials Physics Laboratories, University of Oulu, P.O. Box 4500, FIN- \\ 90014 Oulu, Finland \\ ${ }^{2}$ Advanced Materials Department, Jožef Stefan Institute, Jamova cesta 36, SI-1000 Ljubljana, \\ Slovenia
}

The effect of $\mathrm{BaTiO}_{3}$ particle shape on the properties of $0.98 \mathrm{MgTiO}_{3}-0.02 \mathrm{BaTiO}_{3}$ composite powders was characterized and analyzed using an indirectly coupled open-ended coaxial cavity resonator at gigahertz frequencies. Elongated micrometre sized $\mathrm{BaTiO}_{3}$ particles were found to have a significantly stronger effect on permittivity when compared to composite powders having micro and nano sized spherical $\mathrm{BaTiO}_{3}$ particles. Inclusion permittivities and dielectric loss tangents of composite powders increased from that of pure $\mathrm{MgTiO}_{3}$ powder, 13.3 and 4.6 $\times 10^{-3}$, up to 15.7 and $1.7 \times 10^{-2}$ with needle shaped $\mathrm{BaTiO}_{3}$ particles, respectively. The presented results give valuable information for tailoring the properties of dielectrics which can be utilized in the vast field of electronic component manufacturing.

KEYWORDS: A. ceramics, A. composites, A. electronic materials, D. dielectric properties, D. dielectrics

\section{INTRODUCTION}

Dielectric powdery substances are used in the extensive field of RF and electronics applications, for example, in polymer-ceramic composites and inks for printed electronics applications. These composites may consist of several different powdery parts as well as coatings which together determine both the mechanical and the electrical properties of the final product. Thus, by utilizing different dielectric materials, final products can be tailored to achieve desired properties, such as mechanical flexibility or dielectric losses, permittivity and capacitance in a certain frequency range. In particular, in specific narrowband filter applications a strict permittivity value is required without a compromise in frequency response as a function of operation temperature [1-4]. Therefore, the temperature coefficient can also be one of the limiting factors in the choice of volume ratio of the powdery materials [5-7]. In addition to the dielectric properties and molecular ratios of the materials used, the effective permittivity of composites can also be affected by different particle shapes and sizes. Using, for example, spherical, ellipsoidal, flake or needle shaped nano- and micrometre sized particles, the effect of a surrounding electric field varies, thus changing the total permittivity of the component [8-11]. Yet, the properties of powders and the influence of their particle shape in practice are poorly known, especially at high frequencies.

a) Corresponding author. Electronic mail: mtuhkala@ee.oulu.fi 
In this paper, the effect of $\mathrm{BaTiO}_{3}$ particle shape on dielectric properties of $0.98 \mathrm{MgTiO}_{3}-$ $0.02 \mathrm{BaTiO}_{3}$ composite powders was characterized for the first time in powdery format using an indirectly coupled coaxial cavity resonator.

\section{EXPERIMENTAL}

Dielectric characterization of pure $\mathrm{MgTiO}_{3}$ and $0.98 \mathrm{MgTiO}_{3}-0.02 \mathrm{BaTiO}_{3}$ composite powders was done by using an open-ended coaxial resonator. A comprehensive and detailed description about the characterization method has been presented in journal paper previously reported by Tuhkala et al. [12]. The method was proved to be accurate for the characterization of magnesium and calcium titanate composite powders with varying molar ratios [13]. In the present experiment different sizes and shapes of $\mathrm{BaTiO}_{3}$ particles were dosed into $\mathrm{MgTiO}_{3}$, which is commonly used as the dielectric powder in composite applications, to form $0.98 \mathrm{MgTiO}_{3}-0.02 \mathrm{BaTiO}_{3}$ composite powders [14]. The $\mathrm{MgTiO}_{3}$ was a commercial dielectric powder from Alfa Aesar $(99 \%,+325$ mesh, formula weight $120.21 \mathrm{~g} / \mathrm{mol}$ ). Needle shaped micrometre size $\mathrm{BaTiO}_{3}$ particles (formula weight $233.2 \mathrm{~g} / \mathrm{mol}$, density $5.47 \mathrm{~g} / \mathrm{cm}^{3}$ ) were prepared in the Jožef Stefan Institute, Slovenia. These particles were formed under hydrothermal conditions at $+240{ }^{\circ} \mathrm{C}$ from sodium titanate belts in an alkaline $(\mathrm{CNaOH}=0.07 \mathrm{~mol} / \mathrm{l})$ water solution of barium acetate. These elongated $\mathrm{BaTiO}_{3}$ particles had average thickness and length of $270 \mathrm{~nm}$ and $2 \mu \mathrm{m}$, respectively (Fig. 1).

Spherical shaped $\mathrm{BaTiO}_{3}$ particles were supplied by Alfa Aesar $(99.7 \%$, Metal basis, formula weight $233.19 \mathrm{~g} / \mathrm{mol}$, density $5.85 \mathrm{~g} / \mathrm{cm}^{3}$ ) and Sachtleben (P23757, formula weight $233 \mathrm{~g} / \mathrm{mol}$, density $5.78 \mathrm{~g} / \mathrm{cm}^{3}$ ). The crystal structures of the powder particles were determined using X-ray diffraction and pattern matching (Discover D8, Bruker AXS) between $2 \theta$ angles of 20-70 ${ }^{\circ}$ In the case of $\mathrm{BaTiO}_{3}$ powders, crystal phases were also investigated using TOPAS 4.2. software (Bruker AXS) and Rietveld refinement. In the refinement powders were assumed to have tetragonal and also a very small amount of cubic phases. For the tetragonal structure the $\mathrm{Z}$-coordinate of $\mathrm{Ti}$ and $\mathrm{O}$ atoms were refined, thus allowing for distortion of the tetragonal structure and enabling better fitting. Particle densities of $\mathrm{MgTiO}_{3}$ and $\mathrm{BaTiO}_{3}$ powder particles were measured using Archimedes' method, a pycnometer (Gay-Lussac BlauBrand ${ }^{\circledR}$, Brand Gmbh + Co KG, Germany) and clean de-ionized water. Densities of composite powder particles were calculated using the densities and molar ratios of magnesium and barium titanate powders. Specific surface areas (SSA) were analyzed using the BET-method based on nitrogen gas adsorption on particles at the temperature of liquid nitrogen (ASAP ${ }^{\mathrm{TM}}$ 2020, Micromeritics Instrument Corporation, U.S.A.). Nanoparticle sizes were analyzed using a laser diffraction based method (Beckman Coulter LS 13 320). It should be noted that agglomerates, especially with non-coated nanometre sized particles, may affect the determined particle sizes. Master samples (5 g) were prepared using a precision balance (Precisa XB $620 \mathrm{M}$ ) and thorough dry mixing in geometric series in order to obtain wellhomogenized powder composite mixtures. The master samples were preserved for one week in a silica filled desiccator to avoid moisture adsorption. The dielectric characterization was done at room temperature $\left(+21^{\circ} \mathrm{C}\right)$ and a relative humidity of $16 \%$.

The characterization of pure $\mathrm{MgTiO}_{3}$ and $0.98 \mathrm{MgTiO}_{3}-0.02 \mathrm{BaTiO}_{3}$ composite powders were done using six different volume fractions between 10-50\% of theoretical density which filled the sample cavity $\left(1.092 \mathrm{~cm}^{3}\right)$. In order to get homogenous filling of the cavity vibration and compression were used during the filling process. Frequency responses, i.e., resonance frequency $\left(f_{r}\right)$ and quality factor $(Q)$, of an empty $\left(f_{r}=4.55 \mathrm{GHz}, Q=1200\right)$ and sample filled resonator were measured using a vector network analyzer (Rohde and Schwartz ZVB $20 \mathrm{GHz}$ ) and -35 dB coupling strength. 
Inclusion permittivities of $\mathrm{MgTiO}_{3}$ and $0.98 \mathrm{MgTiO}_{3}-0.02 \mathrm{BaTiO}_{3}$ composite powders were determined using the measurement results of effective permittivities and the mixing equations of Bruggeman symmetric (Eq. 1) and Looyenga (Eq. 2). These equations had previously been found to have good correlation in the characterization of dielectric properties of particles reported by Tuhkala et al., Conger et al. and Nelson et al. [12, 13, 15-18].

$\frac{\varepsilon_{i}-\varepsilon_{\text {eff }}}{\varepsilon_{i}+2 \varepsilon_{\text {eff }}} f+\frac{\varepsilon_{e}-\varepsilon_{\text {eff }}}{\varepsilon_{e}+2 \varepsilon_{\text {eff }}}(1-f)=0$

$\varepsilon_{\text {eff }}{ }^{1 / 3}=(1-f) \varepsilon_{e}{ }^{1 / 3}+f \varepsilon_{i}{ }^{1 / 3}$,

where $\varepsilon_{\mathrm{eff}}, \varepsilon_{\mathrm{e}}, \varepsilon_{\mathrm{i}}$ are the effective permittivity of the medium, permittivities of the matrix (e.g., air, $\left.\varepsilon_{\mathrm{r}}=1.00059\right)$ and inclusion respectively, and $f$ is the volume fraction of the inclusions. Inclusion permittivities were determined at volume fraction 0.43 where the mixing equations define the same theoretical effective permittivity. In addition, a certain compaction level $(f>0.25)$ was required in order to get comparable results as reported by Sheen et al. and Macutkevic et al. [19, 20]. The determined inclusion permittivity was a combination of permittivities of the $\mathrm{MgTiO}_{3}$ and $\mathrm{BaTiO}_{3}$ particles.

The effective loss tangents ( $\tan \delta_{\text {eff }}$ ) of powders were calculated using the differences in quality factors of an empty and sample filled resonator (Eq. 3).

$\tan \delta_{\text {eff }}=\frac{1}{Q_{\text {filled }}}-\frac{1}{Q_{\text {empty }}}$

By using a general mixing model in parallel mode (Eq. 4) and the volume fraction of the dielectric material $\left(f_{\mathrm{d}}\right)$ the dielectric loss tangent $\left(\tan \delta_{\mathrm{d}}\right)$ was derived (Eq. 5). It should be noted that the dielectric loss tangent of the air is close to zero [21].

$\left(\tan \delta_{e f f}\right)^{\alpha}=\sum \mathrm{f}_{i}\left(\tan \delta_{i}\right)^{\alpha}$

$\tan \delta_{d}=\frac{\tan \delta_{e f f}}{f_{d}}$

In the general mixing model (Eq. 4 ) the power $\alpha$ determines the mixing model, i.e., $-1=$ serial, $0=$ logarithmic and $1=$ parallel and the subscript $i$ refers to the volume fraction and dielectric loss tangent of the $\mathrm{i}^{\text {th }}$ material. The parallel mode was shown to have good correlation in the determination of dielectric loss and molar ratios of composite powders reported by Tuhkala et al., Huang et al. and Fukuda et al. [13, 15, 22, 23].

\section{RESULTS AND DISCUSSION}

The addition of different sizes and shapes of $\mathrm{BaTiO}_{3}$ particles resulted in significantly changed dielectric properties when compared to pure $\mathrm{MgTiO}_{3}$ powder (Fig. 2). The increase in effective permittivity was found to be systematic and significant, even with the lowest volume fractions. The highest increase in effective permittivity was observed for the needle shaped $\mathrm{BaTiO}_{3}$ particles 
obtaining an inclusion permittivity of 15.7 for $0.98 \mathrm{MgTiO}_{3}-0.02 \mathrm{BaTiO}_{3}$ composite powder. The spherical shaped nanometre sized $\mathrm{BaTiO}_{3}$ particles caused nearly as great an increase in permittivity with the lowest volume fraction $(f=0.16)$. However, effective permittivities with denser samples were lower than those with the needle shaped particles and thus an inclusion permittivity of 14.2 was determined at volume fraction $f \approx 0.43$ used for comparison. The needle shaped micrometre sized $\mathrm{BaTiO}_{3}$ particles were found to increase effective permittivities of the composite powder rapidly above a volume fraction 0.19 compared to nanometre sized spherical particles. This correlates also with the electrostatic theory [24] and mathematical analysis regarding needle shaped particles reported by Jones et al. [9]. With micrometre sized spherical $\mathrm{BaTiO}_{3}$ particles the effective permittivities of the composite powder were not increased as rapidly as a function of loading, which resulted in a determined inclusion permittivity of 13.7.

As was found with the permittivity, the needle shaped particles also efficiently increased the effective loss tangents resulting in a dielectric loss tangent of $1.7 \times 10^{-2}$ for $0.98 \mathrm{MgTiO}_{3}$ $0.02 \mathrm{BaTiO}_{3}$ inclusions. The spherical shaped $\mathrm{BaTiO}_{3}$ particles increased the dielectric loss tangent from that of pure $\mathrm{MgTiO}_{3}$, i.e., from $4.6 \times 10^{-3}$, to $5.4 \times 10^{-3}$ and $9.7 \times 10^{-3}$ with micro- and nanometre sized $\mathrm{BaTiO}_{3}$ particles, respectively. All measurement results are summarized in Table 1 .

From the results it can be clearly seen that a higher permittivity was reached with needle shaped particles when compared to spherical particles. Because of differences in $\mathrm{BaTiO}_{3}$ particle shapes, percolation and thus also interactions between particles were different and this can affect the permittivity of the composite powder [25]. Correlation with this was found with the measurement results of effective permittivities and loss tangents that increased systematically with all measured powder samples as shown in Fig. 2.

The XRD measurements and Rietveld refinement (inserts) of the $\mathrm{BaTiO}_{3}$ powders are presented in Fig. 3. The P4mm tetragonal and Pm-3m cubic models were selected for the data fitting according to the results from the pattern matching. The relative amount of tetragonal phase was more than $95 \%$ in all of the powders. The highest tetragonality, i.e., the ratio between lattice parameters $\mathrm{c}$ and $\mathrm{a}$, of $\sim 1.009$ was observed with the $1.17 \mu \mathrm{m}$ spherical $\mathrm{BaTiO}_{3}$ particles. The tetragonality of both the $0.15 \mu \mathrm{m}$ spherical and needle shaped particles was $\sim 1.006$. This was also seen as a change in the separation of 002 and 200 peaks in Fig. 3. The $0.15 \mu \mathrm{m}$ spherical particles were found to be slightly less tetragonal than the $1.17 \mu \mathrm{m}$ spherical particles. However, even with such small molar amounts of $\mathrm{BaTiO}_{3}$ particles they still provided a greater change in permittivity (Fig. 4). A similar effect was reported by Dhir et al. [26] and Zou et al. [27] in their researches of nanosize-scale Dy-doped $\mathrm{BiFeO}_{3}$, and the effect of particle size on the $\mathrm{BaTiO}_{3}$ ceramics, respectively. In addition, $\mathrm{M}$. Teirikangas et al. reported that changes in interfaces, due to higher specific surface area, between polymer matrix and nanoparticles were the reason for the increased permittivity [28].

Particles with higher SSA can increase moisture adsorption and the scattering of an incident electromagnetic wave at high frequencies which can increase losses [29]. However, geometrically different form factor can affect magnitude of scattering and thus cause changes in total loss mechanism of the wave [29]. Furthermore, it should be noted that agglomerates of nanoparticles may affect the total permittivity differently compared to optimally distributed composite powders due to interactions between particles [30]. Although the used theoretical models of Bruggeman symmetric and Looyenga are tailored for spherical shaped particles they correlated well with the composite powder containing needle shaped $\mathrm{BaTiO}_{3}$ particles (Fig. 4). This is due to the fact that the needle shaped particles represent only a small fraction of the material. In the case where they 
would be the primary filler, some other equation should be used to take into account the aspect ratio of the particles.

\section{CONCLUSIONS}

Even though the powder components in the presented examples of composite powders were similar regarding their chemical composition, relevant changes in the dielectric properties of $0.98 \mathrm{MgTiO}_{3}-$ $0.02 \mathrm{BaTiO}_{3}$ composite powders were achieved by varying the sizes and shapes of the $\mathrm{BaTiO}_{3}$ particles. The composite powders had remarkable differences in their effective permittivities and loss tangents. The needle shaped micrometre sized $\mathrm{BaTiO}_{3}$ particles had the greatest effect on the effective permittivity amongst all the measured samples, thus resulting in an inclusion permittivity of 15.7 and a dielectric loss tangent of $1.7 \times 10^{-2}$. In addition to the finding that needle shaped particles can affect the permittivity of the composite significantly more than spherical nanoparticles powders, even with low molar ratios, it also highlights the importance of measuring dielectric properties of powdery substances. As demonstrated in the present paper, properties of the final product could be tailored simply by varying the particle shapes of dielectric powdery materials. This information could be utilized, for example, in a production of electrical composites for RF applications.

\section{ACKNOWLEDGEMENT}

The authors gratefully acknowledge the project "Innoinks" 906/31/2010 funded by Tekes (FIN), Sachtleben Pigments Oy (FIN), Pulse Finland Oy (FIN) and NOF Corporation (JAP). The work has received funding from the European Research Council (ERC) grant agreement No. 291132. Author Jari Juuti acknowledges the funding of the Academy of Finland (project numbers 273663 and 267573). 


\section{REFERENCES}

[1] M. Kadota, T. Nakao, T. Murata and K. Matsuda, "Surface acoustic wave filter in high frequency range with narrow bandwidth and excellent temperature property," in IEEE International Ultrasonics Symposium Proceedings, Beijing, 2008.

[2] C.-H. Shen and C.-L. Huang, "Microwave dielectric properties of (Mg0.95Ni0.05) TiO3$\mathrm{SrTiO} 3$ ceramics with a near-zero temperature coefficient of resonant frequency," International Journal of Applied Ceramic Technology, vol. 7, no. 2, pp. 207 - 216, 2010.

[3] A. Yokoi, H. Ogawa and A. Kan, "Microwave dielectric properties of BaO-Ta2O5-TiO2 system," Journal of the European Ceramic Society, vol. 26, no. 10-11, pp. 2069 - 2074, 2006.

[4] C.-L. Huang, C.-L. Pan and J.-F. Hsu, "Dielectric properties of $(1-\mathrm{x})(\mathrm{Mg} 0.95 \mathrm{Co} 0.05) \mathrm{TiO} 3-\mathrm{xCaTiO} 3$ ceramic system at microwave frequency," Materials Research Bulletin, vol. 37, no. 15, p. 2483-2490, 2002.

[5] L. Li, X. M. Chen and C. X. Fan, "Microwave dielectric characteristics and finite element analysis of MgTiO3-CaTiO3 layered dielectric resonators," Journal of the European Ceramic Society, vol. 26, no. 15, pp. 3265-3271, 2006.

[6] P. Fiorenza, R. Lo Nigro, P. Delugas, V. Raineri, A. G. Mould and D. C. Sinclair, "Direct imaging of the core-shell effect in positive temperature coefficient of resistance-BaTiO3 ceramics," Applied Physics Letters, vol. 95, no. 14, pp. 142904-1 -142904-3, 2009.

[7] E. S. Choi, . Y. H. Lee and S. G. Bae, "Microwave dielectric properties of MgTiO3BaTiO3 ceramics," Proceedings of the International Symposium on Electrical Insulating Materials, pp. 99-102, 2001.

[8] R.-B. Yang, W.-F. Liang, S.-T. Choi and C.-K. Lin, "The effects of size and shape of iron particles on the microwave absorbing properties of composite absorbers," IEEE Transactions on Magnetics, vol. 49, no. 7, pp. 4180 - 4183, 2013.

[9] S. B. Jones and S. P. Friedman, "Particle shape effects on the effective permittivity of anisotropic or isotropic media consisting of aligned or randomly oriented ellipsoidal particles," Water Resources Research, vol. 36, no. 10, pp. 2821 - 2833, 2000.

[10] H. S. Göktürk, T. J. Fiske and D. M. Kalyon, "Effects of particle shape and size distributions on the electrical and magnetic properties of nickel/polyethylene composites," Journal of Applied Polymer Science, vol. 50, no. 11, pp. 1891 - 1901, 1993. 
[11] Z.-M. Dang, Y. Zheng and H.-P. Xu, "Effect of the ceramic particle size on the microstructure and dielectric properties of barium titanate/polystyrene composites," Journal of Applied Polymer Science, vol. 110, no. 6, pp. 3473 - 3479, 2008.

[12] M. Tuhkala, J. Juuti and H. Jantunen, "Method to characterize dielectric properties of powdery substances," Journal of Applied Physics, vol. 114, no. 1, 2013.

[13] M. Tuhkala, J. Juuti and H. Jantunen, "An indirectly coupled open-ended resonator applied to characterize dielectric properties of MgTiO3-CaTiO3 powders," Journal of Applied Physics, vol. 115, no. 18, pp. 184101 - 184101-5, 2014.

[14] M. T. Sebastian, "alumina, titania, ceria, tungstate and other materials," in Dielectric materials for wireless communication, Amsterdam, Elsevier Science Publishers, 2008, pp. 425 - 426, 429 - 430, 516 - 517.

[15] M. Tuhkala, J. Juuti and H. Jantunen, "Use of an open-ended coaxial cavity method to characterize powdery substances exposed to humidity," Applied Physics Letters, vol. 103, no. 14, pp. 142907-1-142907-4, 2013.

[16] M. Tuhkala, J. Juuti and H. Jantunen, "Determination of complex permittivity of surfactant treated powdery substances by an open-ended coaxial cavity resonator," Journal of Applied Physics.

[17] N. L. Conger and S. E. Tung, "Measurement of Dielectric Constant and Loss Factor of Powder Materials in the Microwave Region," The Review of Scientific Instruments, vol. 38, no. 3, pp. 384-386, 1967.

[18] S. O. Nelson and P. G. Bartley, "Open-Ended Coaxial-Line Permittivity Measurements on Pulverized Materials," IEEE TRANSACTIONS ON INSTRUMENTATION AND MEASUREMENT, vol. 47, no. 1, pp. 133-137, 1998.

[19] J. Macutkevic and J. Banys, "Comment on "giant dielectric permittivity of detonationproduced nanodiamond is caused by water" by S. S. Batsanov, S. M. Gavrilkin, A. S. Batsanov, K. B. Poyarkov, I. I. Kulakova, D. W. Johnson and B. G. Mendis, J. Mater. Chem., 2012, 22, 11166," Journal of Materials Chemistry C, vol. 1, no. 19, pp. 3255 -3256, 2013.

[20] J. Sheen and Z. W. Hong, "Microwave measurements of dielectric constants by exponential and logarithmic mixture equations," Progress In Electromagnetics Research, vol. 100, pp. 13-26, 2010. 
[21] X. Jin and M. Ali, "Embedded antennas in dry and saturated concrete for applications in wireless sensors," Progress In Electromagnetics Research, vol. 102, pp. 197-211, 2010.

[22] C.-L. Huang and M.-H. Weng, "Improved high q value of MgTiO3-CaTiO3 microwave dielectric ceramics at low sintering temperature," Materials Research Bulletin, vol. 36, no. 15, p. 2741-2750, 2001.

[23] K. Fukuda, R. Kitoh and I. Awai, "Microwave characteristics of TiO2-Bi2O3 dielectric resonator," Japanese Journal of Applied Physics, vol. 32, no. 10, pp. 4584-4588, 1993.

[24] A. Sihvola, "Advanced mixing principles," in Electromagnetic mixing formulas and applications, London, United Kingdom, The Institution of Electrical Engineers, 1999, pp. 61-71.

[25] A. Sihvola, "Special phenomena caused by mixing," in Electromagnetic Mixing Formulas and Applications, London, United Kingdom, The Institution of Electrical Engineers, 1999, pp. 215 - 233.

[26] G. Dhir, P. Uniyal and N. K. Verma, "Effect of Particle Size on Magnetic and Dielectric Properties of Nanoscale Dy-Doped BiFeO3," Journal of Superconductivity and Novel Magnetism, vol. 27, no. 6, pp. 1569 - 1577, 2014.

[27] Y. Zou, Y. Wu, X. Guo, S. Tong, Z. Wang and L. Zhang, "Effect of particle size on the densification and dielectric properties of $\mathrm{BaTiO} 3$ ceramics prepared by liquid phase sintering," Physica Status Solidi. A, vol. 209, no. 2, pp. 243 - 247, 2012.

[28] M. Teirikangas, J. Juuti and H. Jantunen, "Organic-inorganic RF composites with enhanced permittivity by nanoparticle additions," Progress In Electromagnetic Research, vol. 115, pp. 147 - 157, 2011.

[29] A. Sihvola, "Towards higher frequencies," in Electromagnetic mixing formulas and applications, London, United Kingdom, The Institution of Eletcrical Engineers, 1999, pp. 177 - 193.

[30] A. Sihvola, "Classical mixing approach," in Electromagnetic mixing formulas and applications, London, United Kingdom, The institution of Electrical Engineers, 1999, pp. $39-47$.

[31] Alfa Aesar, "Alfa Aesar, Certificate of analysis MgTiO3, LOT J22W049," 9 February 2015. [Online]. Available: http://www.alfa.com. [Accessed 9 February 2015]. 
[32] Alfa Aesar, "Alfa Aesar, Certificate of analysis BaTiO3, LOT 61400271," 9 February 2015. [Online]. Available: http://www.alfa.com. [Accessed 9 February 2015]. 


\section{TABLES}

Table 1. Particle shapes, sizes and $\mathrm{SSA}^{-v a l u e s ~ o f ~} \mathrm{MgTiO}_{3}$ and $\mathrm{BaTiO}_{3}$ particles. Densities and dielectric properties of $\mathrm{MgTiO}_{3}$ and $0.98 \mathrm{MgTiO}_{3}-\mathrm{O}_{2} \mathrm{BBaTiO}_{3}$ composite powder inclusions.

\begin{tabular}{|c|c|c|c|c|c|c|c|}
\hline Powder & $\begin{array}{l}\text { Particle } \\
\text { shape }\end{array}$ & $\begin{array}{c}\text { Particle } \\
\text { size }^{\mathrm{a}} \\
{[\mu \mathrm{m}]}\end{array}$ & $\begin{array}{c}\text { SSA } \\
{\left[\mathrm{m}^{2} / \mathrm{g}\right]}\end{array}$ & $\begin{array}{c}\rho \\
{\left[\mathrm{g} / \mathrm{cm}^{3}\right]}\end{array}$ & $\overline{\varepsilon_{\mathrm{i}}}$ & $\begin{array}{c}\tan \delta_{\mathrm{d}} \\
{\left[\times 10^{-3}\right]}\end{array}$ & Phase \\
\hline$\overline{\mathrm{MgTiO}_{3}}$ & Spherical & $3.06[31]$ & 3.5 & 3.95 & 13.3 & 4.6 & - \\
\hline $\begin{array}{l}0.98 \mathrm{MgTiO}_{3-}- \\
0.02 \mathrm{BaTiO}_{3}\end{array}$ & Needle $^{\mathrm{b}}$ & $2(0.27)^{b}$ & $5.3^{\mathrm{b}}$ & 4.0 & 15.7 & 17 & Tetragonal $^{\mathrm{b}}$ \\
\hline $\begin{array}{l}0.98 \mathrm{MgTiO}_{3-} \\
0.02 \mathrm{BaTiO}_{3}\end{array}$ & Spherical $^{\mathrm{b}}$ & $0.15^{\mathrm{b}}$ & $6.0^{\mathrm{b}}$ & 4.0 & 14.2 & 9.7 & Tetragonal \\
\hline $\begin{array}{l}0.98 \mathrm{MgTiO}_{3-} \\
0.02 \mathrm{BaTiO}_{3}\end{array}$ & Spherical $^{\mathrm{b}}$ & $1.17^{\mathrm{b}}[32]$ & $2.0^{\mathrm{b}}[32]$ & 4.0 & 13.7 & 5.4 & Tetragonal $^{\mathrm{b}}$ \\
\hline
\end{tabular}

${ }^{\mathrm{a}}$ Particle size (d50) where $50 \%$ of particles represent the size.

${ }^{b}$ Properties of $\mathrm{BaTiO}_{3}$ particles. Thickness of the needle shaped $\mathrm{BaTiO}_{3}$ particles in brackets. 


\section{TABLE OF FIGURES}

Fig. 1. SEM figure of elongated $\mathrm{BaTiO}_{3}$ particles.

Fig. 2. Effective permittivity and loss tangent values of composite and $\mathrm{MgTiO}_{3}$ powders as a function of volume fraction. Determined dielectric values of inclusions are presented as inserts. Sizes and shapes of $\mathrm{BaTiO}_{3}$ particles are in brackets. Resonance frequencies of the measurements were within the range of $2.2-3.7 \mathrm{GHz}$.

Fig. 3. X-ray diffraction of the used $\mathrm{BaTiO}_{3}$ powders between $2 \theta$ angles of $20-70^{\circ}$ with orientations. Diffraction between $2 \theta$ angles of $44.5-46$, as insert $(a=$ spherical $0.15 \mu \mathrm{m}, b=$ spherical $1.17 \mu \mathrm{m}$ and $\mathrm{c}=$ needle $2 \mu \mathrm{m}$ ), indicated tetragonal phase.

Fig. 4. Theoretical curves of Bruggeman symmetric and Looyenga mixing models, measured effective permittivities and loss tangents of powder composites as a function of volume fraction. Sizes and shapes of $\mathrm{BaTiO}_{3}$ particles are in brackets. Resonance frequencies of the measurements were within the range of $2.2-3.7 \mathrm{GHz}$.

\section{FIGURES}

Fig. 1.

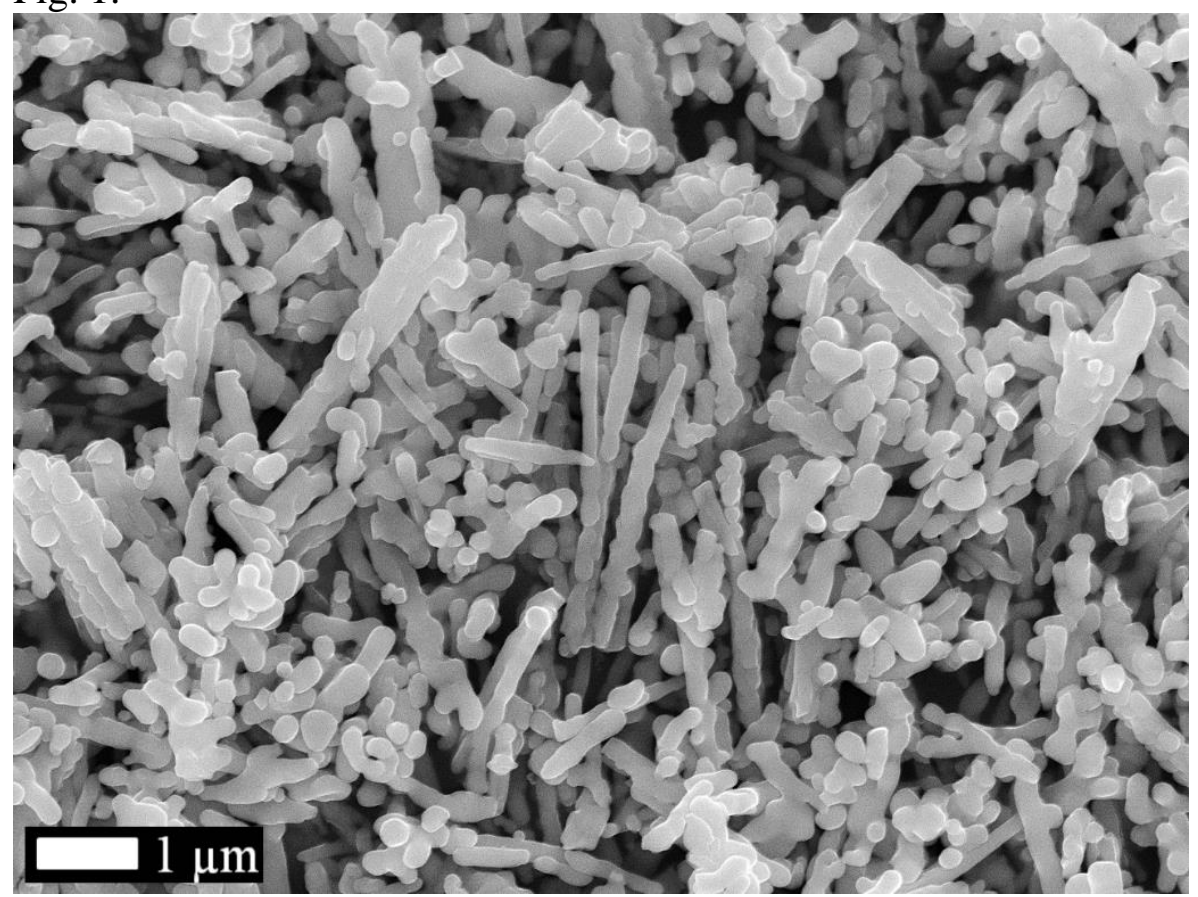


Fig. 2.

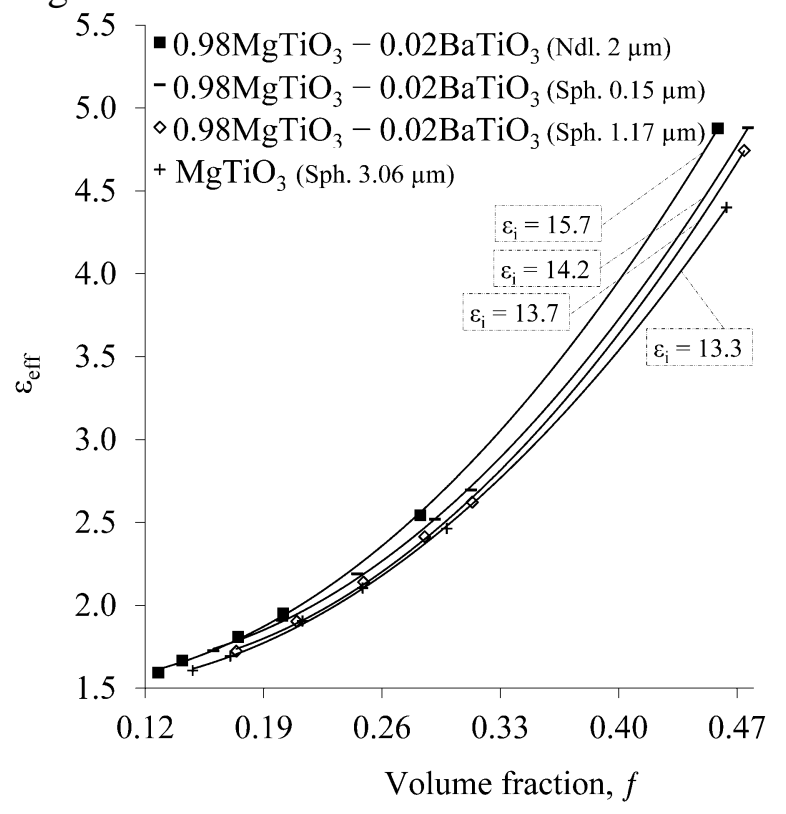

Fig. 3.

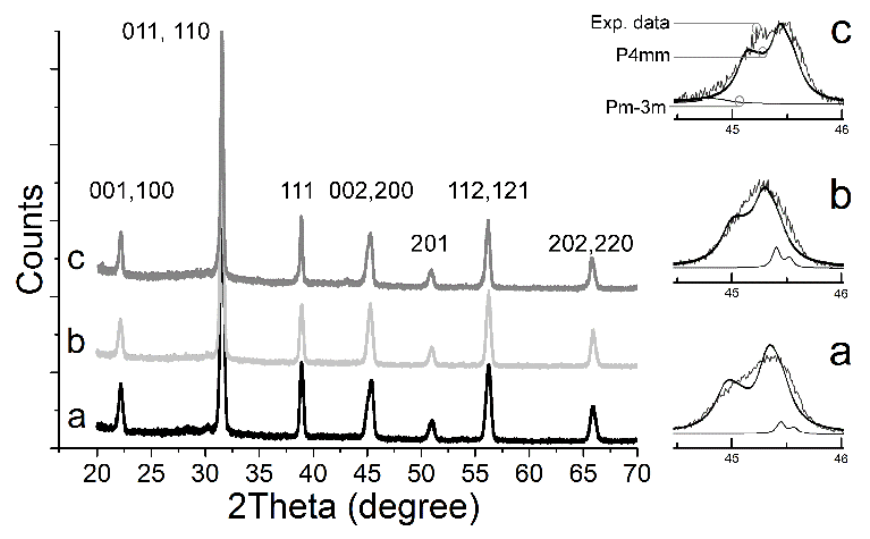

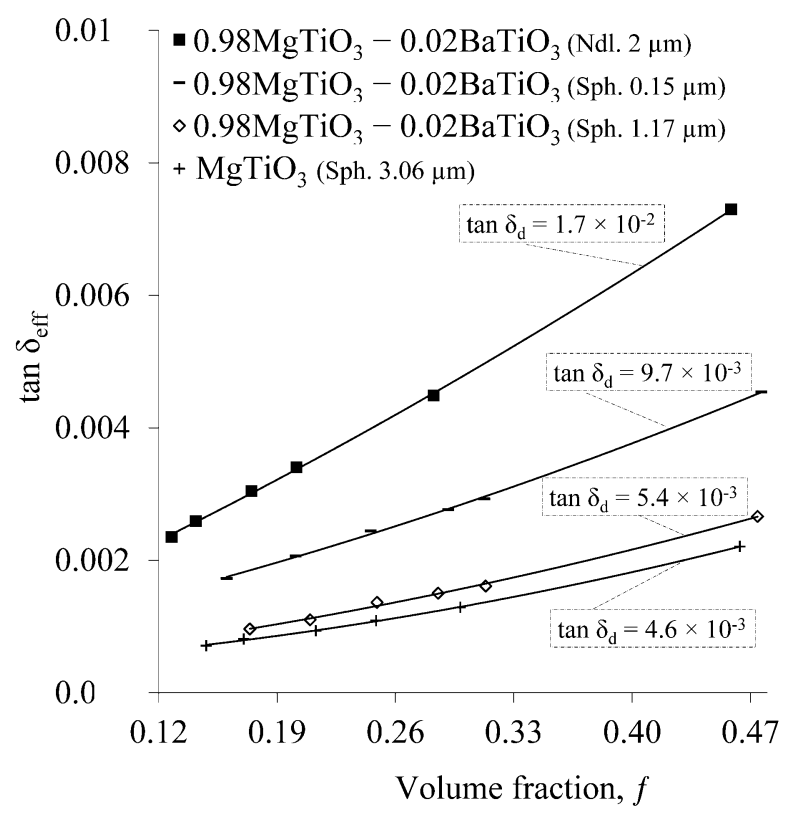


Fig. 4.

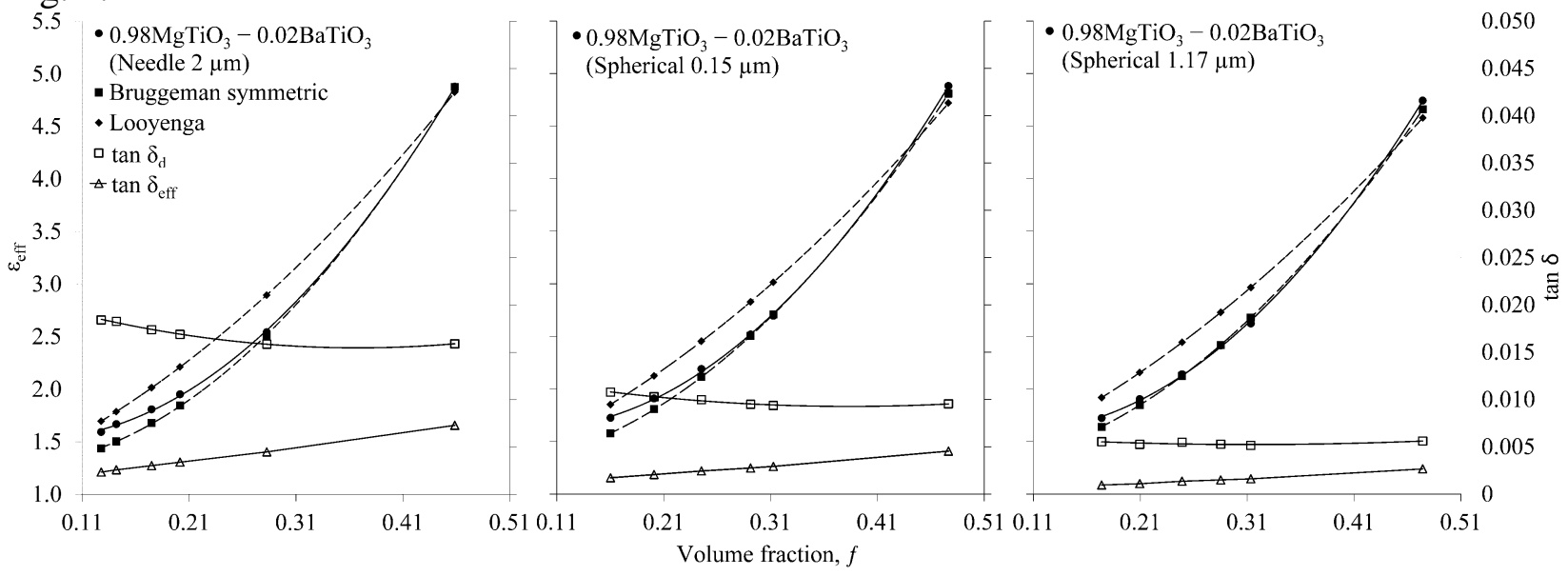

